\title{
К.А. Корзников
}

Ботанический сад-институт ДВО РАН, г. Владивосток, Россия

\section{Сосудистые растения спонтанно зарастающих участков разработки россыпного месторождения золота (р. Лангери, центральный Сахалин)}

\author{
Работа выполнена при поддержке региональной общественной организации \\ «Экологическая вахта Сахалина».
}

\begin{abstract}
Рассматривается соотношение участия растений разных жизненных форм в растительном покрове техногенно нарушенных территорий. Обследованы участки горнопромышленного ландщафта, стихийно зарастающие с 19972010 г2. Выполнено 58 геоботанических описаний на пробных площадях $100 \mathrm{~m}^{2}$, обнаружено 110 видов сосудистых растений. Среднее проективное покрытие сосудистых растений меняется от 5\% на отвалах промытых пород до почти 50\% в межотвальных понижениях. Участие древесных видов и видов многолетних трав значительно превышает участие одно- и двулетников. Среди древесных растений наибольший вклад в сложение растительного покрова вносят деревья пойменных местообитаний (Salix spp., Alnus hirsuta, Populus suaveolens) и Betula platyphylla, среди многолетних трав - Trifolium repens, Chamaenerion angustifolium, Anaphalis margaritacea, Pilosella $\times$ floribunda. Роль древесных растений значительна при зарастании отвалов промытых пород. В межотвальных понижениях их участие сопоставимо с участием многолетних трав. Во всех других типах техногенных экотопов преимущество остается за многолетними травянистыми растениями. Многомерная ординация показала разнонаправленность векторов числа видов древесных растений и их проективного покрытия с векторами общего проективного покрытия, числа видов и проективного покрытия многолетних трав.
\end{abstract}

Ключевые слова: техногенный ландшафт; зарастание; первичная сукиессия; жизненная форма; анализ главных компонент.

\section{Введение}

В ходе разработок месторождений полезных ископаемых возникает особый техногенный горнопромышленный ландшафт [1]. На Дальнем Востоке России площадь территорий с таким ландшафтом неуклонно возрастает [2, 3]. Нарушенные территории оставляют на спонтанное зарастание, реже на отработанных участках недр проводят биологическую рекультивацию. Вопросы восстановления растительного покрова на территориях, нарушенных в ходе добычи полезных ископаемых, остаются малоизученными в регио- 
не и ранее обсуждались в немногих работах, приуроченных к материковым районам юга Дальнего Востока [2-8]. Подобные исследования для Сахалинской области нам неизвестны. Ввиду разнообразия природных условий островного региона и его природной специфики - гористости рельефа, океаничности и муссонного характера климата, расположения на границе ботанико-географических выделов высокого ранга (Восточноазиатской и Бореальной флористических областей Голарктики) - экстраполяция результатов исследований, выполненных в других областях России [9-13] или в иных странах [14-18], в полном объеме невозможна. Это, в свою очередь, накладывает существенные ограничения на возможность осуществления научно обоснованных мероприятий по восстановлению растительного покрова нарушенных территорий.

Целью работы явилось установление участия растений разных жизненных форм в формировании растительного покрова полигонов золотодобычи в верховьях р. Лангери, отработанных в период 1997-2010 гг. и оставленных на спонтанное зарастание.

\section{Материалы и методики исследования}

Район золотодобычи располагается в центральной части острова Сахалин, в Смирныховском административном районе $\left(50^{\circ} 6^{\prime} 21^{\prime \prime} \mathrm{N}, 143^{\circ} 10^{\prime} 23^{\prime \prime} \mathrm{E}\right)$. Средняя высота около 300 м над ур. м., среднегодовая температура $-1,5^{\circ} \mathrm{C}$, среднегодовое количество осадков 535 мм [19]. Растительность горных склонов долины р. Лангери в районе золотоносного месторождения слагают вторичные леса из Larix cajanderi Mayr и Betula platyphylla Sukaczev, которые возникли на месте сведенных коренных темнохвойных лесов из Abies sachalinensis F. Schmidt и Picea ajanensis (Lindl. \& Gordon) Fisch. \& Carr. Участки коренных массивов сохранились на незначительных площадях.

Пойменные и приречные местообитания занимают растительные сообщества с доминированием Alnus hirsuta (Spach) Turcz. ex Rupr. и Salix udensis Trautv. \& C.A. Меу., иногда с локусами Padus avium Mill., Populus suaveolens Fisch., Salix cardiophylla Trautv. \& C.A. Меу. Под их пологом развивается ярус крупных трав, высота которого достигает 2 м и более (Filipendula camtschatica (Pall.) Maxim., Senecio cannabifolius Less., Heracleum lanatum Michx.). Растительные сообщества такого типа были полностью уничтожены в ходе разработки россыпного месторождения. На месте естественной поймы сформировался техногенный ландшафт, состоящий из отвалов промытых золотоносных пород (гале-эфельные отвалы), прудов-илоотстойников, дамб, канав, незадернованных площадей рабочих разрезов и других элементов рельефа. Поскольку золотоносный горизонт располагается на глубине нескольких метров, то днища рабочих разрезов оказываются ниже уровня былой поймы. Перед началом работ речные воды отводят от будущих рабочих разрезов в обводные канавы. Через некоторое время после оконча- 
ния горных работ речные воды стихийным образом проникают на участки рабочих разрезов, размывают отвалы, дамбы и отложения прудов-отстойников, образуют молодую пойму. Горнотехническая и биологическая рекультивации на территории проведения исследовательских работ не выполнялись.

Полевые работы проведены в июле и августе 2015 г. Растительный покров описывали на пробных площадях размером 10×10 и $5 \times 20$ м. В пределах каждой пробной площади выявляли полный состав сосудистых растений и глазомерно оценивали их проективное покрытие, как общее, так и частное. При организации пробной площади особо тщательно следили за тем, чтобы выбранный для геоботанического описания контур как можно более точно характеризовал растительный покров всего экотопа. Исследовали зарастание гале-эфельных отвалов, межотвальных понижений, поверхностей илоотстойников, свежих аллювиальных отложений вдоль речных потоков, молодой поймы.

Обнаруженные на пробных площадях виды разделили на 3 группы жизненных форм: древесные (деревья, кустарники, полукустарники, кустарнички), многолетние травы и малолетние (одно- и двулетние) травы. Во всех геоботанических описаниях для каждой группы вычислили флористическую насыщенность (число видов на 100 м²) и сумму частных проективных покрытий видов. Поскольку проективное покрытие в геоботанических описаниях разных экотопов меняется более чем на порядок, то использовали не только абсолютные (истинные), но и относительные показатели, выраженные в долях от суммы частных покрытий. Аналогичным образом для групп видов устанавливали относительную флористическую насыщенность - долю видов той или иной группы от общего числа видов в описании. Относительные значения числа видов и проективного покрытия использовали для построения трехкомпонентных графиков и проведения процедуры непрямой ординации. Многомерное пространство, образованное восемью фитоцентическими показателями (флористическая насыщенность, общее проективное покрытие сосудистых растений, доли числа видов и проективных покрытий растений трех выделенных групп), упростили, анализируя главные компоненты. Предварительно исходную матрицу со значениями признаков нормализовали путем логарифмического преобразования [20].

Значимость различий при сравнении двух рядов значений определяли с помощью теста Манна-Уитни, при множественном сравнении - с помощью теста Краскела-Уоллиса. Для оценки связей между фитоценотическими показателями и координатами двух первых главных компонент использовали множественную регрессию. Значимость множественной регрессии устанавливали при помощи перестановочного теста с учетом поправки Бонферрони. Статистический анализ и построение диаграмм выполнили в программной среде R с использованием пакетов vegan [21] и ggtern [22].

Названия растений приведены по сводке С.К. Черепанова [23]. Жизненные формы растений указаны по А.Б. Безделеву и Т.А. Безделевой [24]. 


\section{Результаты исследования и обсуждение}

В ходе добычи полезных ископаемых формируется сложный техногенный ландшафт. Результаты полевых исследований позволили выделить пять основных типов экотопов на участках золотодобычи. Гале-эфельные отвалы сложены песчано-каменистым материалом, образованы в результате сгребания бульдозерами промытой на гидроприборах золотоносной породы. Их высоты достигают 10 м, уклоны - 20, а уклоны эродированных склонов $40^{\circ}$ и более. Выявлено, что наибольшее постоянство при зарастании отвалов характерно для $B$. platyphylla $(100 \%$, здесь и далее после названия вида в скобках приведено его постоянство на пробных площадях в рассматриваемом типе экотопа), L. cajanderi (93\%), S. udensis (89\%) и P. suaveolens $(78 \%)$. Проростки и подрост этих видов встречаются на отвалах повсеместно, но большого проективного покрытия не образуют, высота редко превышает 1-1,5 м. К видам травянистых растений с высоким постоянством относятся: Chamaenerion angustifolium (L.) Scop. (89\%), Anaphalis margaritacea (L.) A. Gray (78\%), Pilosella $\times$ floribunda (Wimm. \& Grab.) Fr. (74\%). Общее проективное покрытие сосудистых растений низкое - около 5\%, хотя на отдельных участках может быть значительно выше. Ввиду малого проективного покрытия и раннего сукцессионного статуса совокупности растений на отвалах следует рассматривать как агрегации, предсообщества.

Сообщества межотвальных понижений отличаются существенно более высокой флористической насыщенностью и проективным покрытием, что связано с накоплением мелкозема и органического вещества. Доминантами являются виды рода Salix. Вместе с ними в древесный ярус входят A. hirsuta (100\%) и B. platyphylla (75\%). Эти виды представлены не только проростками и невысоким подростом, но и молодыми деревьями с диаметром ствола более 6 см и высотой до 8 м. Из травянистых растений наиболее часты и обильны Potentilla norvegica L. (75\%), Picris japonica Thunb. (75\%), Trifolium repens L. (75\%), Trifolium pratense L. (75\%), Calamagrostis purpurea (Trin.) Trin. (75\%), а также перечисленные выше виды с гале-эфельных отвалов. Общее проективное покрытие составляет около $50 \%$.

Пруды-илоотстойники созданы для очистки вод, идущих с гидроприборов, от взвеси минеральных частиц. Процессы осаждения (седиментации) приводят к тому, что дно отстойников слагают глинисто-илистые фракции грунта. Мощность отложений может достигать нескольких метров. В растительных сообществах зарастающих отложений прудов-отстойников высоко участие Typha latifolia L. (100\%) и Juncus spp. (83\%). Покрытие T. latifolia в среднем составляет около $20 \%$, а общее проективное покрытие сосудистых растений свыше $30 \%$. К числу часто встречающихся видов относят S. udensis (67\%) и S. schwerenii (50\%), Alisma plantago-aquatica L. (50\%), Equisetum fluviatile L. (50\%). Последний вид, как правило, имеет проективное покрытие около 10\%, но на отдельных площадях может формировать почти сплошной ковер. 
Растительные сообщества на прирусловых аллювиальных отложениях имеют наиболее разнородный видовой состав. Наиболее часто встречаются S. udensis (90\%), T. repens (80\%), T. pratense (80\%). Высокая флористическая насыщенность сопровождается сравнительно малым проективным покрытием и низким постоянством большинства видов. Общее проективное покрытие составляет около 20\%. Выражена закономерность - растения более плотно размещаются на расстоянии 1-2 м от уреза воды, а на большем удалении представлены в виде компактных агрегаций или одиночных особей.

В пределах пространства рабочих разрезов - молодой пойме - высоко постоянство S. udensis (91\%), T. repens (82\%), S. schwerinii (73\%), B. platyphylla (73\%). Частные проективные покрытия видов незначительны, но вследствие высокой флористической насыщенности общее проективное покрытие, как правило, достигает или превышает 30\%. По составу, структуре и физиономичности сообщества молодой поймы напоминают фитоценозы антропогенных ландшафтов острова: первый ярус, часто несомкнутый, сложен мелколиственными видами деревьев, а подчиненный ярус образован многолетними видами трав, преимущественно адвентивными, характерными для рудеральных местообитаний. В целом растительный покров неоднороден, существует в виде сложной мозаики с доминированием того или иного сочетания видов на конкретном участке.

В общей сложности на 58 пробных площадях отмечено 110 видов сосудистых растений, из которых 26 являются древесными (из них 16 - деревья, 8 - кустарники, 1 - полукустарник, 1 - кустарничек), 70 - многолетними травами, 14 - малолетними травами. Участие растений разных жизненных форм в сложении растительного покрова неодинаково в экотопах разных типов (табл. 1).

По числу видов группа древесных растений превосходит группу многолетних трав только на отвалах, но статистически незначимо. Во всех других экотопах число многолетних трав значимо выше числа древесных и малолетних травянистых видов. Несколько иное соотношение складывается между разными группами растений при сравнении их проективных покрытий. Древесные растения образуют большее проективное покрытие на отвалах и в межотвальных понижениях. В растительных сообществах остальных экотопов выше проективное покрытие многолетних трав. Во всех случаях множественных сравнений покрытий растений одной группы в разных экотопах значимых различий не наблюдается. Результаты парных сравнений покрытий разных групп внутри одного экотопа показывают, что участие древесных видов значимо выше на отвалах, а многолетних трав - в пределах молодой поймы. Участие малолетних видов остается незначительным во всех типах экотопов.

Приведенные в табл. 1 медианные значения характеризуют общую тенденцию. На отдельных пробных площадях соотношения между растениями разных групп могут быть отличными от усредненных. 
7
0
0
0
0
0
0
$\exists$
5
5
0
0
6

\begin{tabular}{|c|c|c|c|c|c|c|c|c|}
\hline \multirow{3}{*}{ 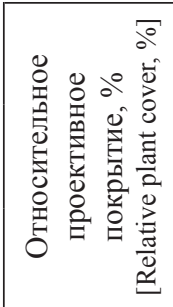 } & $\ll$ & in & $\stackrel{0}{0}$ & $\begin{array}{l}\text { ì } \\
\text { in }\end{array}$ & $\stackrel{i n}{f}$ & مू & 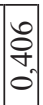 & 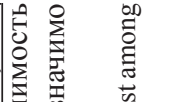 \\
\hline & $\Psi$ & ते & ì & $\frac{i}{6}$ & $\begin{array}{l}\hat{R} \\
\infty \\
\infty\end{array}$ & ڤ̊ & $\mid$\begin{tabular}{l}
$n$ \\
\multirow{f}{*}{} \\
0 \\
0
\end{tabular} & 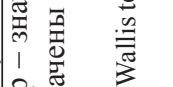 \\
\hline & 3 & $\frac{5}{6}$ & $\begin{array}{l}\mathfrak{a}^{n} \\
\infty \\
i n\end{array}$ & స̃ & $\stackrel{\infty}{=}$ & $\stackrel{\infty}{\infty}$ & $\mid$\begin{tabular}{l}
$n$ \\
\multirow{2}{*}{} \\
0 \\
0
\end{tabular} & 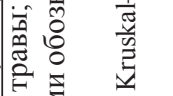 \\
\hline \multirow{4}{*}{ 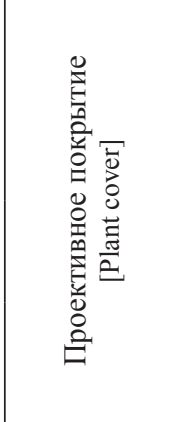 } & $\ll$ & స̇ & है & 离 & $\begin{array}{l}0 \\
0 \\
0\end{array}$ & $\stackrel{\sigma}{\sigma_{0}^{\circ}}$ & $\mid \begin{array}{c}\text { T⿱ } \\
\text { N. } \\
0\end{array}$ & 莬 \\
\hline & $\Psi$ & $\stackrel{8}{0}$ & 雚 & $\stackrel{i}{i}$ & 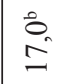 & î & $\left|\begin{array}{c}m \\
n \\
0 \\
0\end{array}\right|$ & 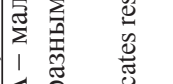 \\
\hline & 3 & $\stackrel{\sim}{\sim}$ & $\begin{array}{l}\stackrel{0}{0} \\
\stackrel{\sim}{d}\end{array}$ & $\stackrel{\widetilde{n}}{\sim}$ & $\stackrel{\tilde{n}}{\sim}$ & $\begin{array}{l}\infty \\
\infty \\
0\end{array}$ & $\left|\begin{array}{c}1 \\
⿱ \\
0 \\
0 \\
0\end{array}\right|$ & 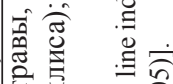 \\
\hline & 造 & in & $\frac{n}{\sim}$ & ల্ল & $\cong$ & ñ & $\begin{array}{l}7 \\
0 \\
0 \\
\hat{v}\end{array}$ & $\begin{array}{ll}0 & 11 \\
1 & 0 \\
0 & 0 \\
010 & 0 \\
0 & 0\end{array}$ \\
\hline \multirow{3}{*}{ 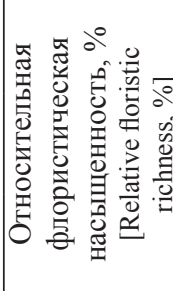 } & $\varangle$ & $\stackrel{2}{2}$ & : & 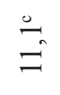 & స̃ & $\begin{array}{l}\tilde{a} \\
\text { ב̃ }\end{array}$ & $\begin{array}{l}\infty \\
0 \\
8 \\
0 \\
0\end{array}$ & $\begin{array}{ll}2 & 5 \\
1 & 5 \\
& 0\end{array}$ \\
\hline & $\Psi$ & 呫 & $\frac{0}{8}$ & $\frac{R}{6}$ & 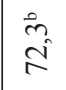 & $\begin{array}{l}\stackrel{R}{T} \\
\stackrel{t}{N}\end{array}$ & $\begin{array}{c}3 \\
0 \\
0 \\
0\end{array}$ & 密 \\
\hline & 3 & مُ & ๙े & 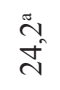 & $\stackrel{\pi}{\tilde{\sigma}}_{0}$ & $\ddot{m}$ & 弪 & $\begin{array}{l}0 \\
\hat{2} \\
0 \\
0\end{array}$ \\
\hline \multirow{4}{*}{ 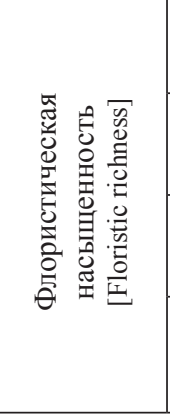 } & $\varangle$ & $\vec{\nabla}$ & $i$ & $\dot{m}$ & $\stackrel{\tilde{n}}{i}$ & ñ & $\left|\begin{array}{l}\infty \\
0 \\
0 \\
0\end{array}\right|$ &. \pm \\
\hline & I & $\Xi$ & in & $\stackrel{8}{0}$ & 吕 & $a^{n}$ & $\left|\begin{array}{l}0 \\
0 \\
0 \\
0\end{array}\right|$ & 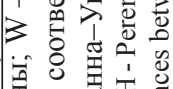 \\
\hline & 3 & Iீ & $\stackrel{\pi}{n}$ & $\tilde{0}$ & $\tilde{m}$ & $\stackrel{\widetilde{N}}{\sim}$ & $\mid$ & $\sum_{\Sigma}^{0} \underset{0}{0}$ \\
\hline & 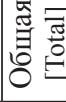 & 6 & $\tilde{n}$ & $\hat{\imath}$ & ते & $\stackrel{n}{ \pm}$ & $\begin{array}{l}1 \\
0 \\
0 \\
0\end{array} \mid$ & 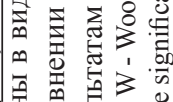 \\
\hline \multicolumn{3}{|l|}{ 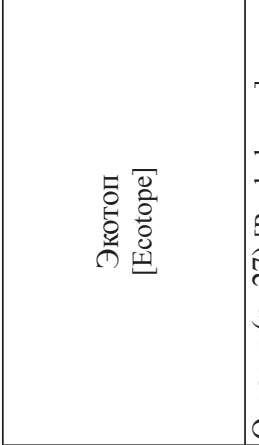 } & 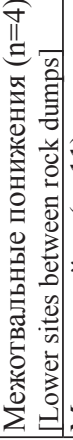 & 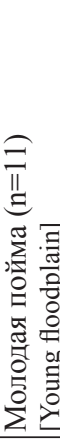 & 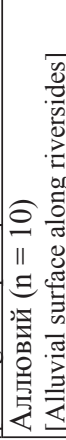 & 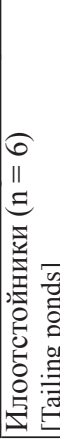 & & 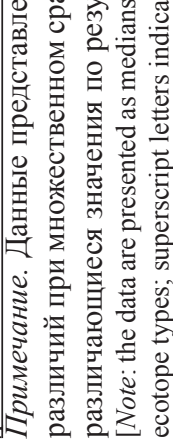 \\
\hline
\end{tabular}


Такие соотношения позволяют оценить тернарные графики (рис. 1). Более или менее существенный вклад малолетних видов в общее проективное покрытие наблюдается только на двух пробных площадях с отвалов, где высоким оказалось покрытие Rhinanthus serotinus (Schonh.) Oborny. По-видимому, это связано с тем, что поверхности отвалов использовались в качестве подъездной рабочей дороги и вследствие этого были перекрыты наносами более продуктивного грунта.

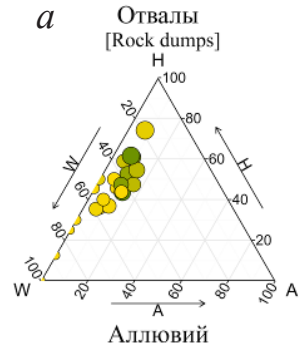

[Alluvial surface along riversides]

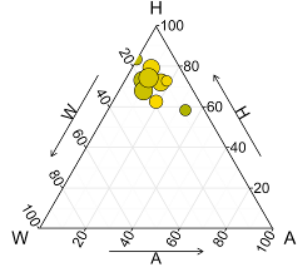

$b$

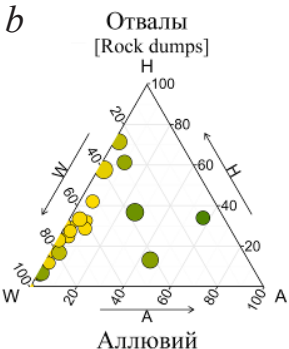

[Alluvial surface along riversides]

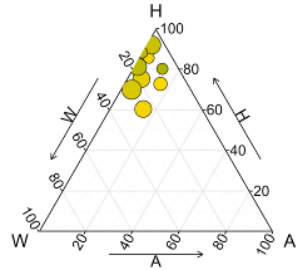

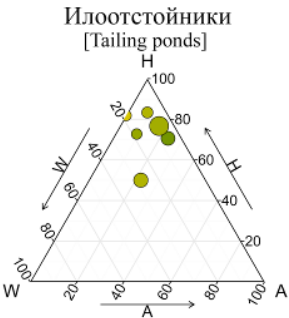

Молодая пойма

[Young floodplain]
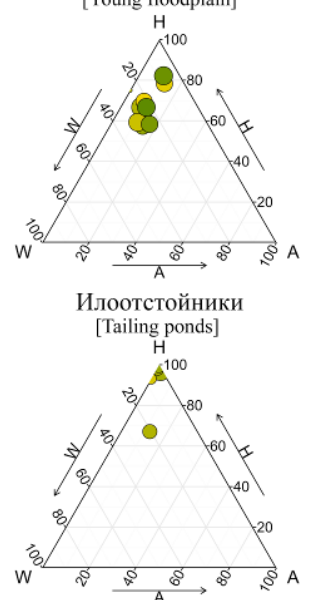

Молодая пойма [Young floodplain]

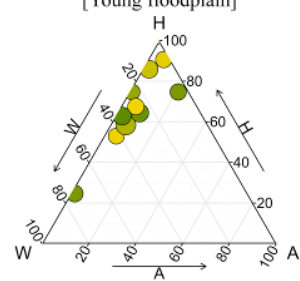

Межотвальные понижения [Lower sites between rock dumps]

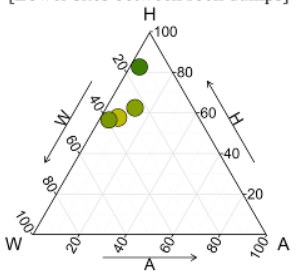

Проективное покрытие, \% [Plant cover, \%]

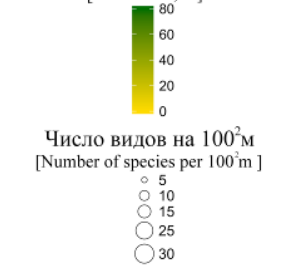

Межотвальные понижения [Lower sites between rock dumps]

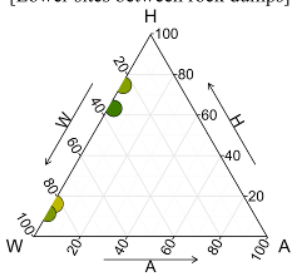

Проективное покрытие, \% [Plant cover, \%]

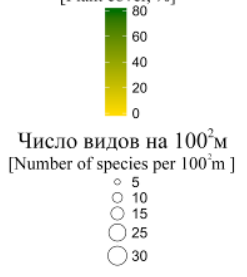

Рис. 1. Участие растений разных групп по числу видов $(a)$ и проективному покрытию $(b): \mathrm{W}$ - древесные растения, $\mathrm{H}$ - многолетние травы, А - малолетние травы [Fig. 1. Participation of plants of different groups according to the number of species $(a)$ and plant cover $(b)$ : W - Woody plants, H - Perennial herbs, A - Annual and biennial herbs] 
Диаграммы многомерной непрямой ординации фитоценотических показателей представлены на рис. 2.
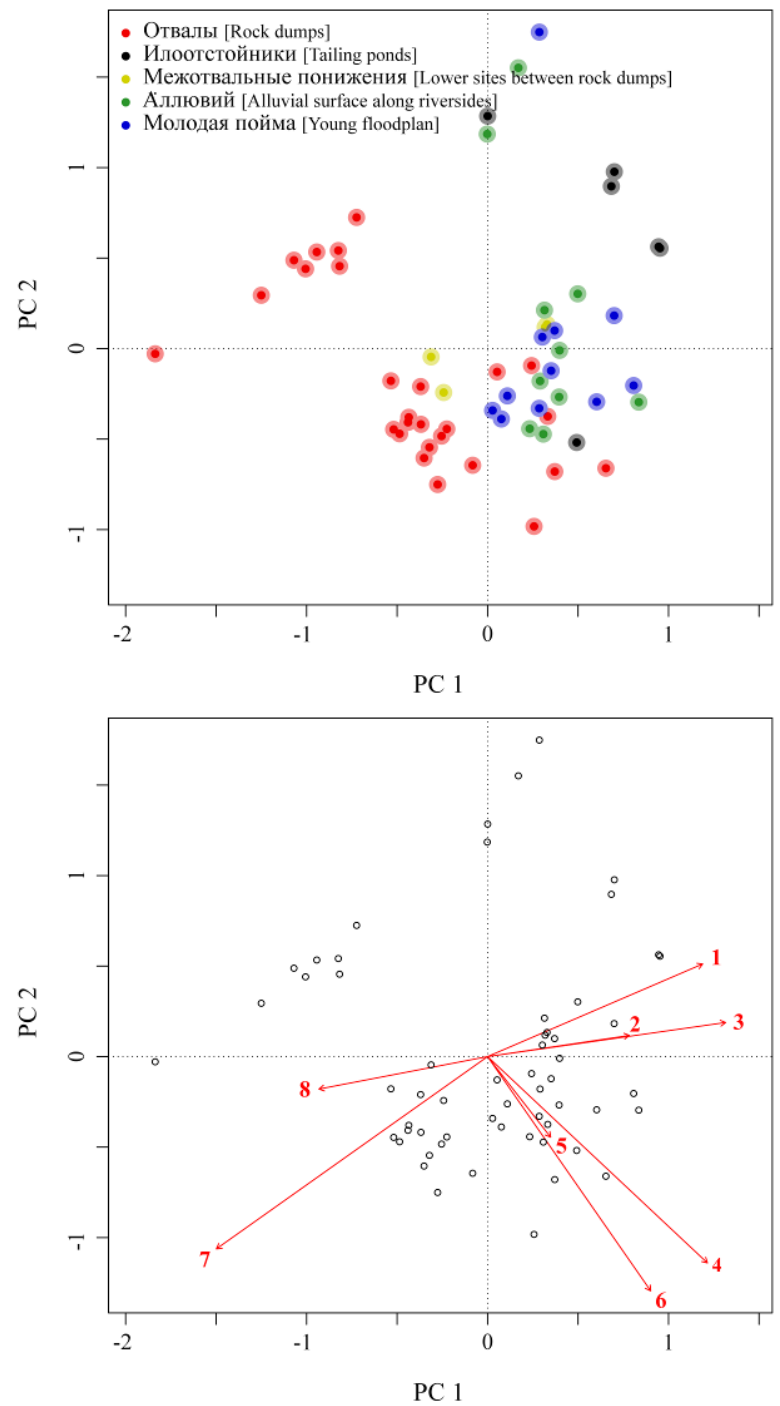

Рис. 2. Результаты анализа главных компонент: 1 - доля проективного покрытия многолетних трав; 2 - доля числа видов многолетних трав; 3 - общее проективное покрытие; 4 - доля числа видов малолетних трав; 5 - флористическая насыщенность;

6 - доля проективного покрытия малолетних трав; 7 - доля проективного покрытия древесных видов; 8 - доля числа видов древесных растений [Fig. 2. PCA results of plant community attributes in sample plots: 1 - Relative cover of perennial herbs, 2 - Relative number of perennial herb species, 3 - Total plant cover, 4 - Relative number of annual and biennial herb species, 5 - Floristic richness, 6 - Relative cover of annual and biennial herbs, 7 - Relative cover of woody plants, 8 - Relative number of woody species] 
Первые две оси варьирования объясняют 47,44 и $23,74 \%$ общей дисперсии. Первая ось тесно и положительно коррелирует с долей числа видов травянистых многолетников и их относительным проективным покрытием (табл. 2).

Т а б л и ц а 2 [Table 2]

\section{Корреляции координат анализа главных компонент с фитоценотическими показателями}

[Correlation of PCA coordinates and plant community attributes]

\begin{tabular}{|c|c|c|c|c|c|}
\hline \multirow{2}{*}{$\begin{array}{l}\text { Показатель } \\
\text { [Attributes] }\end{array}$} & \multicolumn{2}{|c|}{$\begin{array}{c}\text { Направление } \\
\text { вектора } \\
\text { [Vector direction] }\end{array}$} & \multicolumn{2}{|c|}{$\mathrm{R}$} & \multirow[t]{2}{*}{$\mathrm{R}^{2}$} \\
\hline & $\begin{array}{c}\text { Oсь } 1 \\
{[\text { Axis } 1]}\end{array}$ & $\begin{array}{c}\text { Ось } 2 \\
{[\text { Axis 2] }}\end{array}$ & $\begin{array}{l}\text { Oсь } 1 \\
{[\text { Axis } 1]}\end{array}$ & \begin{tabular}{|c|} 
Ось 2 \\
{$[$ Axis 2] } \\
\end{tabular} & \\
\hline $\begin{array}{l}\text { Флористическая насыщенность } \\
\text { [Floristic richness] }\end{array}$ & 0,727 & $-0,686$ & 0,496 & $-0,468$ & 0,466 \\
\hline $\begin{array}{l}\text { Общее проективное покрытие } \\
\text { [Total plant cover] }\end{array}$ & 0,998 & 0,059 & 0,561 & 0,033 & 0,316 \\
\hline $\begin{array}{l}\text { Доля древесных видов } \\
\text { [Relative number of woody species] }\end{array}$ & $-0,996$ & $-0,095$ & $-0,906$ & $-0,087$ & 0,828 \\
\hline $\begin{array}{l}\text { Доля многолетних видов трав } \\
\text { [Relative number of perennial herb species] }\end{array}$ & 0,948 & 0,317 & 0,799 & 0,267 & 0,709 \\
\hline $\begin{array}{l}\text { Доля малолетних видов трав } \\
\text { [Relative number of annual and biennial herb species] }\end{array}$ & 0,827 & $-0,563$ & 0,658 & $-0,448$ & 0,634 \\
\hline $\begin{array}{l}\text { Покрытие древесных растений (доля) } \\
\text { [Relative cover of woody species] }\end{array}$ & $-0,927$ & $-0,376$ & $-0,839$ & $-0,340$ & 0,821 \\
\hline $\begin{array}{l}\text { Покрытие многолетних трав (доля) } \\
\text { [Relative cover of perennial herbs] }\end{array}$ & 0,828 & 0,560 & 0,752 & 0,509 & 0,825 \\
\hline $\begin{array}{l}\text { Покрытие малолетних трав (доля) } \\
\text { [Relative cover of annual and biennial herbs] }\end{array}$ & 0,572 & $-0,820$ & 0,338 & $-0,489$ & 0,349 \\
\hline
\end{tabular}

Примечание. $\mathrm{R}$ - коэффициент линейной корреляции Пирсона, $\mathrm{R}^{2}-$ доля объясненной дисперсии множественной регрессии; шрифтом выделены наиболее тесные связи; результаты множественной регрессии статистически значимы по результатам перестановочного теста $(\mathrm{n}=999, \mathrm{p}=0,008$ с учетом поправки Бонферрони).

[Note: $\mathrm{R}$ - the Pearson correlation coefficient, $\mathrm{R}^{2}$ - proportion of explained variance in multiple regression; the strongest correlations are in bold; permutation test was used to test significance of multiple regression ( $\mathrm{n}=999, \mathrm{p}=0.008$ with the Bonferroni correction)].

Тесная отрицательная корреляция с первой осью варьирования наблюдается для доли числа древесных видов и их относительного проективного покрытия. Со второй осью варьирования наиболее тесно положительно коррелирует относительное покрытие многолетних трав, а отрицательно относительное покрытие малолетних трав. Направления векторов и корреляции признаков с осями варьирования определяют, что на ординационной диаграмме левее и выше располагаются точки геоботанических описаний с большим числом и участием древесных видов, но меньшим общим проективным покрытием. Правее - более флористически богатые, с высоким участием травянистых растений. Антагонизм участия древесных и многолетних травянистых растений подтверждается разнонаправленностью их 
векторов. Векторы флористической насыщенности и участия травянистых малолетников почти сонаправлены. Таким образом, в растительном покрове действует закономерность: чем выше общее проективное покрытие и участие травянистых растений, тем меньше участие древесных растений. Результаты ординации подтверждают неоднородность растительного покрова техногенного ландшафта и различие фитоценотических показателей растительных сообществ разных типов экотопов.

Несмотря на то, что число видов кустарников лишь немного меньше числа видов деревьев, их роль в сложении растительных сообществ невелика. Для большинства видов кустарников характерны низкое постоянство и незначительное проективное покрытие. Из растений этой жизненной формы наиболее часто встречается Duschekia fruticosa (Rupr.) Pouzar. Вид отмечен в $20 \%$ геоботанических описаний отвалов и молодой поймы, где имеет проективное покрытие от 0,2 до 40\%. Кустарничек Vaccinium vitis-idaea L. обнаружен на одной пробной площади, его проективное покрытие составило $0,2 \%$. Полукустарник Rubus sachalinensis H. Lev. обнаружен на трех пробных площадях, его максимальное проективное покрытие составило всего $0,6 \%$.

Такие виды деревьев, как Salix caprea L., S. udensis, S. schwerenii (имеет две формы - древовидную и кустарниковую), A. hirsuta, P. suaveolens, произрастают во всех типах экотопов, но на отложениях илоотстойников имеют меньшее постоянство. Подрост L. cajanderii приурочен в основном к отвалам промытых пород, что отмечено и для участков золотодобычи в Приамурье [25], в пределах илоотстойников и на молодом аллювии не встречается. Проростки и подрост деревьев $P$. ajanensis, A. sachalinensis, доминантов зональных климаксовых сообществ, произрастают на отвалах с постоянством 63 и $15 \%$ соответственно и диапазоном проективного покрытия $0,05-0,2 \%$. В других экотопах техногенного ландшафта эти виды почти не встречаются. Подрост интродуцированной на Сахалине Pinus sylvestris L. отмечен на отвалах и на территории молодой поймы. В целом типичные пойменные виды деревьев демонстрируют тенденцию хорошего возобновления, причем не только в пределах площадей рабочих разрезов, трансформировавшихся в молодую пойму, но и на малопродуктивных поверхностях гале-эфельных отвалов.

В ходе разработки полезных ископаемых при уничтожении почвеннорастительного покрова условия среды настолько сильно меняются по сравнению с изначальными, что восстанавливающиеся растительные сообщества не могут быть идентичны исходным [14]. Появление видов-доминантов из состава сообществ завершающих стадий сукцессии уже на первых этапах восстановления растительного покрова горнопромышленных ландшафтов отмечается во многих работах $[3,5,15,17,18]$, но выражено далеко не всегда и не во всех регионах $[11,16]$.

Раннее появление древесных видов из состава климаксовых и субклимаксовых растительных сообществ на первичных субстратах может приво- 
дить к парадоксальным на первый взгляд явлениям - первичные сукцессии способны проходить быстрее (т.е. растительный покров достигает климакса или приближенного к климаксу состояния), чем вторичные [26]. С другой стороны, в особо маргинальных условиях, например гале-эфельных отвалов, сукцессионный процесс протекает крайне медленно, а наличие древесных видов объясняется обильным поступлением диаспор с прилегающих ненарушенных участков, дальнейшим приживанием растений в наиболее благоприятных микросайтах и скорой гибелью ввиду ограниченности их ресурсов. Подобное явление в научной литературе получило название «массэффект» [27]. Хорошей иллюстрацией принципа масс-эффекта служит отмеченное С.Ю. Гришиным [28] на молодых лавовых полях вулкана Толбачик явление - рост прижившихся деревьев продолжается до момента исчерпания ресурсов конкретного микросайта. Для поверхностей гале-эфельных отвалов, судя по всему, характерна та же закономерность - постоянный поток диаспор из окружающих сообществ обусловливает наличие проростков и молодого подроста деревьев, существующих тем не менее без перспективы скорого формирования сомкнутого древесного яруса. В пользу этого свидетельствует тот факт, что проростки и подрост деревьев отвалов, зарастающих даже с 1997 г. (и с более раннего времени на других участках месторождения), очень редко представлены экземплярами выше 2 м, а их проективное покрытие остается незначительным. Единственным исключением является A. hirsuta, вид, ассоциированный с азотфиксирующими актиномицетами рода Frankia [29], что, по-видимому, позволяет растениям более или менее успешно развиваться в малопродуктивных экотопах.

Незначительное участие одно- и двулетних растений объясняется, по всей видимости, не вполне подходящим комплексом условий для видов с облигатно рудеральной стратегией (в смысле J.P. Grime [30], согласно терминологии Л.Г. Раменского [31], - эксплерентов), отсутствием семенных банков и устойчивого потока диаспор из фоновых лесных фитоценозов, в сложении которых эти растения не принимают существенного участия. Инициальные стадии восстановления растительного покрова в сходных типах экотопов горнопромышленных ландшафтов Центральной Европы, напротив, сформированы преимущественно малолетними видами трав [16].

Многолетние травы формируют основу растительного покрова молодой поймы, отложений илоотстойников и свежего аллювия вдоль речных потоков. Видовой состав группы многолетних трав имеет крайне мало общих видов как с лесными сообществами на бортах долины р. Лангери, так и с пойменными ненарушенными фитоценозами. Очевидно, что травянистые виды пойменных сообществ, в отличие от деревьев, не в состоянии колонизовать нарушенный субстрат, вследствие чего наблюдается несоответствие состава разных ярусов: под типичными доминантами пойменных лесов формируется травяной ярус из многолетних трав, характерных для рудеральных местообитаний. 


\section{Заключение}

Результаты проведенного исследования показали, что горнопромышленный ландшафт, возникший вследствие разработки россыпного месторождения золота на р. Лангери, неоднороден и состоит из экотопов разного типа. Установлено, что неоднородную пространственную структуру принимает и спонтанно развивающийся растительный покров. На первых этапах зарастания нарушенных территорий участвуют сосудистые растения разных жизненных форм. Выявлено, что в зависимости от типа экотопа на начальных стадиях первичной сукцессии преимущество получают деревья или многолетние травы. Вклад деревьев в сложение растительного покрова наиболее высок при зарастании гале-эфельных отвалов и межотвальных понижений. Показано высокое постоянство и проективное покрытие деревьев-доминантов пойменных крупнотравных лесов долины р. Лангери. Кустарники, полукустарники и кустарнички существенной роли в формировании фитоценозов на нарушенных территориях не играют. Установлено, что многолетние травы доминируют на участках молодой поймы, свежих аллювиальных отложениях вдоль речных потоков и отложениях илоотстойников. В то же время малолетние травы как по числу видов, так и по проективному покрытию значительно уступают двум другим группам жизненных форм сосудистых растений.

За помощь в изысканиях выражаю признательность В.В. Ковалевскому (волонтер РОО «Экологическая вахта Сахалина») и К.Б. Поповой (ассистент кафедры геоботаники МГУ им. М.В. Ломоносова).

\section{Лuтература}

1. Осипов C.B., Гуров А.А. Детальное картографирование техногенных ландшафтов // География и природные ресурсы. 2016. № 1. С. 156-163.

2. Ивакина E.B., Якубов B.B., Осипов C.B. Сосудистые растения участка угледобычи «Лузановский» (российский Дальний Восток) // Сибирский экологический журнал. 2013. Т. 20, № 2. С. 234-247.

3. Осипов С.В., Ивакина Е.B. Растительный покров карьерно-отвальных комплексов в дальневосточных лесостепных ландшафтах // Ботанический журнал. 2016. Т. 101, № 1. C. 45-63.

4. Осипов C.B. Серийная растительность участков золотодобычи в таежной зоне Нижнего Приамурья // Ботанический журнал. 2006. Т. 91, № 4. С. 521-532.

5. Осипов С.В., Черданцева В.Я., Галанина И.А., Якубов В.В. Видовой состав и экологоценотические спектры сосудистых растений, мхов и лишайников на участках золотодобычи в таежной зоне Нижнего Приамурья (Дальний Восток) // Сибирский экологический журнал. 2008. Т. 15, № 4. С. 553-569.

6. Шлотгауэр С.Д. Антропогенная динамика растительности Хабаровского края // Вестник Дальневосточного отделения Российской академии наук. 1993. № 6. С. 84-90.

7. Шлотгауэр С.Д. Антропогенная динамика и возобновление растительности на горнопромышленных отвалах речных пойм Охотии // Научные и практические 
аспекты добычи цветных и благородных металлов: доклады международного совещания / ред. Ю.А. Мамаев, В.Г. Крюков. Ч. 2. Хабаровск: ИГД ДВО РАН, 2000. C. $473-482$.

8. Шляхов C.A., Осипов С.B. Техногенные поверхностные образования на месте разработки россыпных месторождений золота (Буреинское нагорье, Дальний Восток) // Почвоведение. 2004. № 10. С. 1250-1258.

9. Капелькина Л.П., Сумина О.И., Лавриненко И.А., Лавриненко О.В., Тихменев Е.А., Миронова С.И. Самозарастание нарушенных земель Севера. СПб.: Изд-во ВВМ, 2014. $204 \mathrm{c}$.

10. Манаков Ю.А., Стрельникова Т.О., Куприянов А.Н. Формирование растительного покрова в техногенных ландшафтах Кузбасса. Новосибирск : Изд-во СО РАН, 2011. 168 с.

11. Сумина О.И., Копиева Е.М. Разнообразие и динамика растительности карьеров в лесотундре Западной Сибири (окрестности г. Лабытнанги, Ямало-Ненецкий АО) // Растительность России. 2004. № 6. С. 83-103.

12. Сумина О.И., Бельдиман Л.Н. Зарастание карьеров лесотундры Западной Сибири: прогноз восстановительных сукцессий // Вестник Санкт-Петербургского университета. Серия 3. Биология. 2011. № 2. С. 13-27.

13. Сумина О.И. Формирование пространственной структуры растительных сообществ в ходе первичной сукцессии // Ботанический журнал. 2012. Т. 97, № 10. С. 1351-1363.

14. Borgegard S.-O. Vegetation development in abandoned gravel pits: effects of surrounding vegetation, substrate and regionality // Journal of Vegetation Science. 1990. Vol. 1, № 5. PP. 675-682.

15. Holl K.D. Long-term vegetation recovery on reclaimed coal surface mines in the eastern USA // Journal of Applied Ecology. 2002. Vol. 39, № 6. PP. 960-970.

16. Rehounkova K., Prach K. Spontaneous vegetation succession in disused gravel-sand pits: Role of local site and landscape factors // Journal of Vegetation Science. 2006. Vol. 17, № 6. PP. 583-590.

17. Sebelikova L., Rehounkova K., Prach K. Spontaneous revegetation vs. forestry reclamation in post-mining sand pits // Environmental Science and Pollution Research. 2016. Vol. 23, № 14. PP. 13598-13605.

18. Takeuchi K., Shimano K. Vegetation succession at the abandoned Ogushi sulfur mine, central Japan // Landscape and Ecological Engineering. 2009. Vol. 5, № 1. PP. 33-44.

19. Архив климатических данных. URL: http://climatebase.ru/station/32076 (дата доступа: 28.08.2016).

20. McCune B., Grace J.B. Analysis of ecological communities. Gleneden Beach, Oregon: MjM Software Design, 2002. 300 p.

21. Oksanen J. Multivariate analysis of ecological communities in R: vegan tutorial. 2015. URL: http://cc.oulu.fi/ jarioksa/opetus/metodi/vegantutor.pdf (дата доступа: 28.08.2016).

22. Ternary diagram in R. URL: http://www.ggtern.com/ (дата доступа: 28.08.2016).

23. Черепанов C.K. Сосудистые растения России и сопредельных государств (в пределах бывшего СССР). СПб. : Мир и семья, 1995. 992 с.

24. Безделев А.Б., Безделева Т.А. Жизненные формы семенных растений российского Дальнего Востока. Владивосток : Дальнаука, 2006. 296 с.

25. Осипов С.В., Бурундукова О.Л. К характеристике лиственницы Каяндера (Larix cajanderi Mayr) на дражных отвалах Приамурья // Экология. 2005. № 4. С. 259-263.

26. Prach K., Tichy L., Lencova K., Adamek M., Koutecky T., Sadlo J., Bartosova A., Novak J., Kovar P., Jirova A., Smilauer P., Rehounkova K. Does succession run towards potential natural vegetation? An analysis across seres // Journal of Vegetation Science. 2016. Vol. 27, № 3. PP. 515-523.

27. Shmida A., Ellner S. Coexistence of plant species with similar niches // Vegetatio. 1984. Vol. 58, № 1. PP. 29-55. 
28. Гришин С.Ю. Сукцессии растительности на лавовых потоках Толбачинского дола // Ботанический журнал. 1992. Т. 77, № 1. С. 92-100.

29. Tobita H., Hasegawa S.F., Yazaki K., Komatsu M., Kitao M. Growth and N2 fixation in an Alnus hirsuta (Turcz.) var. sibirica stand in Japan // Journal of Biosciences. 2013. Vol. 38, № 4. PP. 761-776.

30. Grime J.P. Plant strategies and vegetation processes. Chichester: JohnWiley \& Sons, 1979. $371 \mathrm{p}$.

31. Раменский Л.Г. Введение в комплексное почвенно-геоботаническое исследование земель. М. : Сельхозгиз, 1938. 620 с.

Поступила в редакцию 24.05.2016 г.; повторно 29.08.2016 г.; принята 19.10.2016 г.; опубликована 13.12.2016 г.

Корзников Кирилл Александрович - канд. биол. наук, с.н.с. лаборатории флоры Дальнего Востока Ботанического сада-института ДВО РАН (690024, г. Владивосток, Россия, ул. Маковского 142).

E-mail: korzkir@mail.ru

Korznikov KA. Spontaneous revegetation of post-mining areas (the Langeri River placer gold deposit, Central Sakhalin, Russia). Vestnik Tomskogo gosudarstvennogo universiteta. Biologiya - Tomsk State University Journal of Biology. 2016;4(36):62-78. doi: 10.17223/19988591/36/5. In Russian, English summary

\section{Kirill A. Korznikov}

Botanical Garden-Institute, Far Eastern Branch of the Russian Academy of Sciences, Vladivostok, Russian Federation

\section{Spontaneous revegetation of post-mining areas (the Langeri River placer gold deposit, Central Sakhalin, Russia)}

The aim of this study was to investigate the role of different vascular plants' life forms in post-mining vegetation cover at the Langeri river placer gold deposit, central Sakhalin, Russia $\left(50^{\circ} 6^{\prime} 21^{\prime \prime N}, 143^{\circ} 10^{\prime} 23^{\prime \prime} E\right)$. Post-mining areas were left for spontaneous revegetation from 1997 to 2010 . 58 relevés at $10 \times 10 \mathrm{~m}$ and $5 \times 10 \mathrm{~m}$ plots were completed in five ecotope types. There were rock dumps after trammel operation, lower sites between rock dumps, tailing ponds, open pit mine areas ("young floodplain" after the river water penetration in the mining area) and young alluvial surfaces along riversides. The relative number of species and the relative plant cover for each group was counted in sample plots. A ternary graph was used to display relative contribution of species groups. PCA with log conversion for initial matrix was used to transform multiple data: six relative plant communities' attributes, total plant cover and floristic richness.

This research has identified 25 woody, 78 perennial and 17 annual and biennial herb species. Salix udensis, S. schwerinii, Betula platyphylla, Populus suaveolens are frequent and abundant in the woody group. Trifolium repense, Chamaenerion angustifolium, Anaphalis margaritacea, Pilosella $\times$ floribunda and Typha latifolia (exclusively in tailing ponds) dominated among herbs. The role of woody plants is great at rock dumps, but the total cover in this ecotope is low (5\%, in average). Perennial herbs dominated in open pit mining areas (cover $20 \%$ ), tailing pond surface (cover $35 \%$ ) and young alluvial surface along riversides (cover 15\%). The total cover of woody and perennial plants at lower sites between rock dumps is about $60 \%$. Annual and biennial species abundance is low in all ecotope types (cover $0.2-0.4 \%$ ). Plant community species composition at 
post-mining sites is conditioned by seed rains from the surrounding areas. Although seeds of the surrounding dominant trees germinate on pits and tailings, the herbaceous layer at all sites is specific and is characterized by low cover. PCA shows that the vectors of the relative number and the relative cover of woody species and the vectors of the total plant cover, the relative number and the relative cover of perennial herb species are oppositely directed. The study results conclude that the initial stages of spontaneous revegetation in post-mining areas occur with vascular plants of different life forms. The dominance of plants of a particular life form depends on the ecotope type. The revegatation measures in post-mining areas should take into consideration the peculiarities of all heterogeneous ecotopes and their ability to support plants of different life forms.

Funding: This work was supported by Non-Governmental Organization "Sakhalin Environment Watch".

Acknowledgments: The author thanks VV Kovalevsky (volunteer of the "Sakhalin Environment Watch") and KB Popova (assistant of the Department of Geobotany, MV Lomonosov Moscow State University) for assistance with the survey.

The article contains 2 Figures, 2 Tables, 31 References.

Key words: post-mining; revegetation; primary succession; plant life-form; PCA.

\section{References}

1. Osipov SV, Gurov AA. Detailed mapping of technogenic landscapes. Geography and Natural Resources. 2016;1:156-163. In Russian

2. Ivakina EV, Osipov SV, Yakubov VV. Vascular plants of the Luzanovskii open-pit coalmining station (Russian Far East). Contemporary Problems of Ecology. 2013;6(2):187-198. doi: 10.1134/S1995425513020054

3. Osipov SV, Ivakina EV. Vegetation cover of the pit-dump complexes in the far eastern forest-steppe landscapes. Botanicheskiy zhurnal - Botanical journal. 2016;101(1):45-63. In Russian, English summary

4. Osipov SV. Serial vegetation of gold mining sites in the Taiga zone of the lower Amur River basin. Botanicheskiy zhurnal - Botanical journal. 2006;91(4):521-532. In Russian, English summary

5. Osipov SV, Cherdantseva VYa, Galanina IA, Yakubov VV. Species composition and ecologophytocenotic spectra of vascular plants, mosses, and lichens on gold-mining sites in the taiga zone of the lower Amur River basin, the Russian Far East. Contemporary Problems of Ecology. 2008;1(4):425-439. doi: 10.1134/S1995425508040061

6. Shlotgauer SD. Anthropogenic vegetation dynamics of Khabarovsk region vegetation. Vestnik Dal'nevostochnogo otdeleniya Rossiyskoy akademii nauk [Proceedings of the Far Eastern Branch of the Russian Academy of Sciences]. 1993;6:84-90. In Russian

7. Shlotgauer SD. Antropogennaya dinamika i vozobnovlenie rastitel'nosti na gornopromyshlennykh otvalakh rechnykh poym Okhotii [Anthropogenic dynamics and revegetation at industrial mining dumps of Okhotia river floodplains]. In: Nauchnye i prakticheskie aspekty dobychi tsvetnykh i blagorodnykh metallov. Doklady mezhdunarodnogo soveshchaniya [Scientific and practical aspects of production of nonferrous and precious metals]. Vol. 2. Mamaev YuA. Mamaev, Kryukov VG, editors. Khabarovsk: Institute of Mining of the Far Eastern Branch of the Russian Academy of Sciences Publ.; 2000. pp. 473-482. In Russian

8. Shlyakhov SA, Osipov SV. Technogenic surface formations in the areas of placer gold mining (the Bureya Upland, Far East). Eurasian Soil Science. 2004:37(10):1106-1114.

9. Kapel'kina LP, Sumina OI, Lavrinenko IA. Tikhmenev EA, Mironova SI. Samozarastanie narushennykh zemel' Severa [Spontaneous revegetation of disturbed areas in the Russian North]. St. Petersburg: VVM Publ.; 2014. 204 p. In Russian 
10. Manakov YuA, Strel'nikova TO, Kupriyanov AN. Formirovanie rastitel'nogo pokrova $\mathrm{v}$ tekhnogennykh landshaftakh Kuzbassa [Vegetation cover formation in technogenic landscapes of Kuzbass]. Novosibirsk: Nauka, Siberian Branch Publ.; 2011. 168 p. In Russian

11. Sumina OI, Koptseva EM. Vegetation diversity and dynamics on quarries in forest-tundra of Northwest Siberia (neighborhood of Labytnangi town, Yamalo-Nenets Autonomous Area). Rastitel'nost'Rossii - Vegetation of Russia. 2004;6:83-103. In Russian, English summary

12. Sumina OI, Beldiman LN. Natural vegetation recovery on quarries in the forest-tundra of Western Siberia: predictions of recovery. Vestnik Sankt-Peterburgskogo universiteta. Seriya 3. Biologiya - Vestnik of Saint-Petersburg University. Series 3. Biology. 2011;2:13-27. In Russian, English summary

13. Sumina OI. Development of spatial structure of plant communities in the course of primary succession. Botanicheskiy zhurnal - Botanical journal. 2012;97(10):1351-1363. In Russian, English summary

14. Borgegard SO. Vegetation development in abandoned gravel pits: effects of surrounding vegetation, substrate and regionality. Journal of Vegetation Science. 1990;1(5):675-682. doi: $10.2307 / 3235575$

15. Holl KD. Long-term vegetation recovery on reclaimed coal surface mines in the eastern USA. Journal of Applied Ecology. 2002;39(6):960-970. doi: 10.1046/j.1365-2664.2002.00767.x

16. Rehounkova K, Prach K. Spontaneous vegetation succession in disused gravel-sand pits: Role of local site and landscape factors. Journal of Vegetation Science. 2006;17(6):583590. doi: 10.1111/j.1654-1103.2006.tb02482.x

17. Sebelikova L, Rehounkova K, Prach K. Spontaneous revegetation vs. forestry reclamation in post-mining sand pits. Environ Sci Pollut Res. 2016;23(14):13598-13605. doi: 10.1007/ s11356-015-5330-9

18. Takeuchi K, Shimano K. Vegetation succession at the abandoned Ogushi sulfur mine, central Japan. Landscape Ecol Eng. 2009;5(1):33-44. doi: 10.1007/s11355-008-0057-0

19. Climatebase.ru. Archive of climate data. Available at: http://climatebase.ru/station/32076 (accessed 28.08.2016).

20. McCune B, Grace JB. Analysis of ecological communities. Gleneden Beach, Oregon: MjM Software Design; 2002. 300 p.

21. Oksanen J. Multivariate analysis of ecological communities in R: vegan tutorial. Available at: http://cc.oulu.fi/ jarioksa/opetus/metodi/vegantutor.pdf (accessed 28.08.2016).

22. Ggtern: Ternary diagram in R. Available at: http://www.ggtern.com/ (accessed 28.08.2016).

23. Cherepanov SK. Vascular plants of Russia and adjacent states (The Former USSR). St. Petersburg: Mir \& Sem'ya Publ.; 1995. 991 p. In Russian

24. Bezdelev AB, Bezdeleva TA. Zhiznennye formy semennykh rasteniy rossiyskogo Dal'nego Vostoka [Life forms of seed plants in the Russian Far East]. Vladivostok: Dal'nauka Publ.; 2006. 296 p. In Russian

25. Osipov SV, Burundukova OL. Characteristics of Cajander larch (Larix cajanderi Mayr) on dredging waste dumps in the Amur region. Russian Journal of Ecology. 2005;36(4):234238. doi: 10.1007/s11184-005-0066-2

26. Prach K, Tichy L, Lencova K, Adamek M, Koutecky T, Sadlo J, Bartosova A, Novak J, Kovar P, Jírova A, Smilauer P, Rehounkova K. Does succession run towards potential natural vegetation? An analysis across seres. J Veg Sci. 2016:27(3):515-523. doi: 10.1111/ jvs. 12383

27. Shmida A, Ellner S. Coexistence of plant species with similar niches. Vegetatio. 1984;58(1):29-55. doi: 10.1007/BF00044894

28. Grishin SYu. Suktsessii podgol'tsovoy rastitel'nosti na lavovykh potokakh Tolbachinskogo dola [Successions of subalpine vegetation on lava flows of the Tolbachik area]. Botanicheskiy zhurnal - Botanical journal. 1992:77(1):92-100. 
29. Tobita H, Hasegawa SF, Yazaki K, Komatsu M, Kitao M. Growth and $\mathrm{N}_{2}$ fixation in an Alnus hirsuta (Turcz.) var. sibirica stand in Japan. Biosci. 2013;38(4):761-776. doi: 10.1007/s12038-013-9369-9

30. Grime JP. Plant strategies and vegetation processes. Chichester: John Wiley \& Sons; 1979. $371 \mathrm{p}$.

31. Ramenskiy LG. Vvedenie v kompleksnoe pochvenno-geobotanicheskoe issledovanie zemel' [Introduction to complex soil and geobotanical investigations]. Moscow: Sel'khozgiz Publ.; 1938. 620 p. In Russian

Received 24 May 2016; Revised 29 August 2016; Accepted 19 October 2016; Published 13 December 2016.

\section{Author info:}

Korznikov Kirill A, Cand. Sci. (Biol.), Senior Researcher, Laboratory of Far Eastern Flora, Botanical Garden-Institute, Far Eastern Branch of the Russian Academy of Sciences, 142 Makovskogo Str., Vladivostok 690024, Russian Federation.

E-mail: korzkir@mail.ru 